\title{
Finansal Performansın Yüzde Yöntemi ile Analizi: Galatasaray A.Ş.'ye Yönelik Bir Uygulama
}

\author{
DOI: 10.26466/opus.970515
}

$*$

\author{
Cevdet Kizil ${ }^{*}$ - Tunay Aslan** \\ * Doç. Dr., İstanbul Medeniyet Üniversitesi, İstanbul/Türkiye \\ E-Posta: \\ cevdetkizil@yahoo.com \\ ORCID: $\quad \underline{0000-0003-0196-2386}$ \\ ** Doç. Dr., Siirt Üniversitesi, Siirt/Türkiye \\ E-Posta: \\ tunay aslan@hotmail.com \\ ORCID: $\underline{0000-0002-0363-6691}$
}

Öz

Bu çalışmada, Galatasaray A.Ş.'nin 31.05.2016 - 31.05.2018 tarihleri arasında kamuyla paylaşılmış bilançosundan ve 01.06.2016 - 31.05.2018 tarihleri arasında kamuyla paylaşılmış gelir tablosundan yararlanılarak, mali tablolarındaki yüzdelik değiş̧imler ile belirtilen değiş̧imlerin olası nedenleri belirlenmeye çalışılmıştır. Dolayısıyla, analize 2015-2017 dönemine ait mali tablolar dahildir. Araştırma bulgularına göre, Galatasaray A.Ş.'nin satışların maliyeti kalemi her iki dönem için de net satışlar (hasılat) kaleminden daha yüksektir. Genel yönetim giderleri ile pazarlama giderleri de artmaktadır. İşletmenin finansman giderleri de yükselmektedir. Firmanın net işletme sermayesi negatiftir. İşletmenin dönen varlıkları, kısa vadeli yabancı kaynaklarını karşılayamamaktadır. Aynı zamanda, işletme öz sermaye ağırlıklı bir kaynak yapısına sahip değildir. Firma, kısa vadeli yabancı kaynaklar ve uzun vadeli yabancı kaynaklar ile finanse edilmektedir. Firmanın finansal borçlarının ticari borçlarından yüksek olması da esnekliğe imkan tanımaması nedeniyle tehlikelidir. Galatasaray A.Ş.'nin diğer alacaklar kaleminin artması da negatif bir durumdur. Ayruca, firmanm negatif öz sermayeye sahip olması, geçmiş yıl zararları ve net dönem zararı ile karşı karşıya olması finansal risk ve kırılganlık teşkil etmektedir. Firmanın stokların eritmesi ve ticari alacaklarını azaltması ise pozitif hususlardir.

Anahtar Kelimeler: Muhasebe, Finans, Dikey Analiz, Futbol, Galatasaray. 


\title{
Investigation of Financial Performance with Vertical Analysis: An Implementation on Galatasaray A.Ş.
}

\begin{abstract}
This study used Galatasaray A.Ş.'s public balance sheets dated between 31.05.2016 - 31.05.2018 and public income statements dated between 01.06.2016 - 31.05.2018 to determine the percentage changes on its financial statements as well as probable reasons of these mentioned changes. Thus, financial statements dated 2015-2017 ae included in the analyses. Based on research findings, costs of sales of Galatasaray A.Ş. is higher than its net sales for both periods. Also, general administrative expenses and marketing expenses are increasing. Additionally, financial expenses of the company are increasing as well. Net capital of the organization is negative. Plus, current assets of the firm can not match its short-term liabilities. Besides, the company does not have an owner's equity weighted resource structure. The organization is financed with short-term and long-term liabilities. The fact that firm's financial liabilites are higher than its commercial liabilities is dangerous, since this condition eliminates flexibility. Morover, it is a negative issue that Galatasaray A.Ş.'s other receivables account is highering. Furthermore, the fact that company owns negative owner's equity, experiences losses for previous periods and faces net loss for the term signals financial risk and fragility. However, the organization is lowering its inventories and its commercial receivables are decreasing, which are positive indicators.
\end{abstract}

Key Words: Accounting, Finance, Vertical Analysis, Football, Galatasaray. 


\section{Giriş}

Küreselleşmeyle beraber birçok alanda yaşanan gelişmeler, özellikle muhasebe ve finans alanlarında da önemli değişimleri ve riskleri beraberinde getirmiştir (Kızıl, Hanişoğlu ve Aslan, 2019). Günümüz dünyasında rekabetin hızla artması, yabancı kaynağa olan ihtiyaç ve bu ihtiyacın hangi koşullarda, nerelerden elde edileceği işletmelerin karşılaştığı önemli riskleri oluşturmaktadır (Kızıl, Kahve ve Aydınyılmaz, 2013). İşletmelerin kıt kaynak yetersizliğine çözüm bulması ve bu kaynakları en düşük maliyetle sağlanması finansal analizi önemli kılmaktadır. Bu durum bütün işletmeler için önemli olmakla beraber, futbol kulüpleri için de önem taşımaktadır. Futbol kulüplerinde yaşanan yoğun rekabet finansal analizin önemini arttırmakta olup, bu etkiyi en alt seviyeye indirmek için işletme kaynaklarının verimli kullanılması gerekmektedir. Etkin bir finans yönetiminin temel fonksiyonları finansal planlama ve kontrol olup, bunların gerçekleşmesi ise etkin bir finansal analize bağlıdır (Kodal, 2017, s.645).

Finansal analiz, bir işletmenin finansal durumunu ve finansal bakımdan gelişiminin yeterli olup olmadığını saptamak için finansal tablolarda yer alan kalemlerde meydana gelen değişimlerin zaman içerisinde göstermiş olduğu eğilimlerin incelenmesi ve ihtiyaç duyulması halinde belirlenen standartlar ve sektör ortalamalariyla karşılaştırarak yorumlayan bir bilim dalıdır. Bir diğer ifade ile finansal analiz, işletme paydaşlarına (yatırımcılar, borç verenler, yöneticiler ve tedarikçiler) verecekleri kararlarda yardımcı olmak için diğer bilgilerle birlikte finansal verilerin seçilmesi, değerlendirilmesi ve yorumlanması hususunda yol gösteren bir araçtır. Finansal analiz çalışanların performansı, faaliyetlerin etkinliği ve kredi politikaları gibi konularda şirket içinden yapılabileceği gibi, yatırım kararlarının verilmesi ve borç ödeme gücünün tespiti gibi kararlarda işletme dişından da yapilabilmektedir. (Ozolgun, 2017, s.55-62; Tekin, 2017, s.25).

Finansal analiz, işletmelerin finansman dengesinin (varlık-kaynak dağılımı) uygun olup olmadığı, işletmelerin pazardaki yeri ve önemi hakkında bizlere önemli bilgiler sunmaktadır. Finansal analiz ayrıca işletmelerin güçlü ve zayıf yönlerini ortaya koymakta olup, bu da işletmeye yatırım yapmak isteyen taraflara fırsat sunmaktadır. Böylece 
finansal analiz, işletmeyi finansal anlamda okumayı sağlayarak bilgi kullanıcılarına rehberlik etmektedir (Şen, Zengin ve Yusubov, 2015, s.6485).

$\mathrm{Bu}$ çalışmada işletmelerin finansal durumu açısından önem taşıyan finansal analiz ve bu analiz yöntemlerinden birisi olan dikey analiz yöntemi örnek bir uygulamayla açıklanmaya çalışılmıştır. Bu amaç doğrultusunda, çalışmanın birinci bölümünü giriş kısmı oluşturmuştur. Daha sonra, konuyla ilgili literatür taraması gerçekleştirilmiş, finansal analizin bir yöntem olarak uygulandığı akademik çalışmalara yer verilmiştir. Çalışmanın sonraki bölümünde ise finansal analiz yöntemleri ve özellikleri açıklanmıştır. Çalışmanın uygulama bölümünde ise Galatasaray A.Ş.'nin 2015- 2017 dönemlerine ait finansal tablolarından (bilanço ve gelir tablosu) yararlanılarak finansal analiz yöntemlerinden birisi olan dikey yüzde yöntemi kullanılmış, finansal durum analiz edilmiştir. Çalışmanın son bölümünde ise sonuç kısmı yer almaktadır.

\section{Literatür Taraması}

Kizıl ve Aslan (2019), Borsa İstanbul'da (BİST) işlem gören havayolu şirketleri üzerine bir araştırma yapmışlardır. Belirtilen çalışmada oran analizi (rasyo analizi) yöntemi kullanılmıştır. Türk Hava Yolları A.Ş. ve Pegasus Hava Yolları A. Ş.'nin finansal performansı 2013-2017 periyodu için rasyo analizi (oran analizi) aracılığıyla incelenmiştir. Havayolları şirketlerinin finansal performansının analiz çalışması için firmaların bilanço ve gelir tablolarından yararlanılmıştır. İşletmelere ait mali tablolar, Kamuyu Aydınlatma Platformu'ndan (KAP) alınmıştır. $\mathrm{KAP}^{\prime} \tan$ alınan veriler, çalışmanın amacına paralel olarak 17 oranın hesaplanmasında kullanılmıştır.

Bilici ve Aydın (2018), yapmış oldukları çalışmada konaklama işletmelerini ele almışlardır. Konaklama firmalarının 2011-2016 yılları arasındaki mali tablolarından yararlanılmıştır. Finansal performansın ölçülmesinde karşılaştırmalı tablolar analizi, trend analizi, oran analizi ve yüzde yöntemini kullanmışlardır.

Akyüz, Yıldırım ve Akyüz (2017), yaptıkları çalışmada borsada işlem gören orman ürünleri ve sanayi sektöründe yer alan işletmeleri ele almışlardır. Firmaların 2015-2016 yıllarına ait bilanço ve gelir 
tablosundaki değişimleri dikey yüzde yöntemi kullanarak analiz etmişlerdir. Değişimlerin işletme açısından önemini de yorumlamışlardır.

Aslan (2017), yapmış olduğu çalışmada borsaya kota olmuş dört büyük Türk futbol takımının finansal performansını oran yöntemi ile analiz etmiştir. Futbol kulüplerinin 2014-2016 yıllarına ait finansal tabloları kullanılmıştır. Araştırmanın sonucunda futbol kulüplerinin borçlarını ödemede zorluk çektiği, sermayelerinin ağırlıklı olarak negatif olduğu gözlenmiştir.

Çatı, Eş ve Özevin (2017), çalışmalarında futbol kulüplerinin sportif etkinliklerini Entropi ve TOPSIS yöntemi kullanarak analiz etmişlerdir. Çalışmada, Avrupa'nın beş büyük futbol kulübü değerlendirilmiştir. Sonuç olarak yüksek transfer harcamaları ile yüksek başarı arasında bir ilişkiye rastlanmamıştır.

Karadeniz, Beyazgül, Dalak ve Günay (2017), Türk turizm sektöründe finansal performansı dikey yüzde yöntemi ile incelemişlerdir. Hisseleri borsada işlem gören turizm şirketlerinin finansal performansının ölçülmesinde dikey yüzde yöntemi kullanılmıştır. Çalışmada turizm şirketlerinin 2014 yılına ait finansal tabloları ve Türkiye Cumhuriyet Merkez Bankası'nın (TCMB) yayınladığı konaklama ve yiyecek hizmet faaliyetleri alt sektörünün finansal tabloları dikey analiz yöntemi kullanılarak incelenmiştir.

Ersoy, Çıtak ve Gülal (2015), futbol endüstrisi üzerinde bir çalışma gerçekleştirmişlerdir. Çalışmanın evrenini Türkiye'deki 4 büyük futbol kulübü ile Avrupa'daki 15 futbol kulübü oluşturmaktadır. 2012-2013 yılları arasında Türkiye' de yer alan 4 büyük futbol kulübü ile Avrupa'da yer alan 15 futbol kulübünün transfer harcamaları ile etkinlikleri, veri zarflama yöntemi kullanılarak karşılaştırılmıştır.

Omağ (2014), gıda sektörünü ele alan bir çalışma gerçekleştirmiştir. Bu çalışmanın evrenini, Türkiye'de faaliyet gösteren büyük ölçekli bir gıda firması oluşturmaktadır. Bahse konu olan gida firmasının, 20112012 yıllarına ait finansal tablolarındaki değişim dikey yüzde yöntemi kullanılarak analiz edilmiştir.

Sakınç (2014), futbol endüstrisi üzerinde bir araştırma gerçekleştirmiştir. Çalışmanın evrenini Türkiye'deki dört büyük futbol 
takımı oluşturmaktadır. 2009-2013 yılları arasında dört büyük futbol takımının finansal performansları oran analizi yöntemi ile incelenmiştir.

Singh ve Schmidgall (2013), Amerika Birleşik Devletleri'nde (ABD) bir çalışma yürütmüşlerdir. $\mathrm{Bu}$ araştırma, turizm sektöründe gerçekleştirilmiştir. Yapılan çalışmada, $\mathrm{ABD}^{\prime}$ de faaliyet gösteren otellerin mali yapısı mercek altına alınmış ve karlılık analizleri dikey yüzde yöntemi ile gerçekleştirilmiştir.

Yahya, Ali, Mir, Yaqoob ve Khan (2013), Pakistan gida sektörü üzerinde bir çalışma gerçekleştirmişlerdir. Bu çalışmada iki şirketin 2008- 2011 yıllarına ait finansal performansları ölçülmüştür. Araştırmada dikey yüzde yöntemi, diğer analiz teknikleriyle beraber kullanılmıştır.

Bardia (2012), yaptığ1 çalışmada Hindistan'da faaliyet gösteren sektörün en büyük iki çelik imalat şirketinin finansal sıkıntı durumunu ve uzun dönemli ödeme gücünü ortaya koymak amacıyla bir çalı̧̧ma yapmıştır. Çalışmada 1997-2009 yılları arasındaki finansal tablolardan faydalanarak şirketlerin finansal sıkıntı durumlarını ortaya koymak amacıyla Altman Z Skoru Modeli kullanılmıştır. Uzun dönemli ödeme gücünün ortaya koyulması amacıyla ise dikey analiz yönteminden yararlanılmıştır.

Vanipriya ve Venkatramaraju (2012), çimento sektörünü ele almışlardır. Çimento sektörünün finansal performansının ölçümü amaçlanmıştır. Bu doğrultuda, çimento sektöründe faaliyet gösteren işletmelerin finansal performansları dikey yüzde yöntemi kullanılarak analiz edilmiştir.

Özyürek ve Erdoğan (2011), İstanbul Menkul Kıymetler Borsası (İMKB) odaklı bir çalışma gerçekleştirmişlerdir. İMKB'de işlem gören finansal firmalar araştırmanın evrenini oluşturmaktadır. Bu firmaların 2009-2010 yıllarına ait finansal performansları, dikey yüzde yöntemi kullanılarak analiz edilmiştir.

Dimitropoulos (2010), futbol endüstrisi üzerine bir çalışma gerçekleştirmiştir. 1994-2004 yılları arasında Yunan futbol kulüplerinin finansal performansı oran yöntemi ile analiz edilmiştir. Sonuç olarak, kulüplerin borçlarının varlıklarının çok üzerinde olduğu ve zarar ettikleri saptanmıştır.

Gürkan (2009), basın işletmeleri üzerine bir araştırma yapmıştır. Yapmış olduğu çalışmada basın işletmelerinin finansman ihtiyaçlarını 
nasıl karşıladıklarını ortaya koymak amacıyla dikey analiz ve oran analizi tekniklerini kullanmıştır. Çalışmada Türkiye' de faaliyet gösteren iki büyük basın işletmesinin 2007-2008-2009 yıllarına ait finansal tabloları kullanılarak dikey analiz ve oran analizi tekniklerinden yararlanılmıştır.

Buraimo, Simmons ve Szymanski (2006), çalışmalarında İngiliz futbol kulüplerinin finansal performanslarını analiz etmiştir. Çalışmanın evrenini İngiliz Premier Ligi (Premier League) ve alt liglerde yer alan futbol kulüpleri oluşturmaktadır. Sonuç olarak yüksek futbolcu bonservis bedelleri ve düzenli olmayan gelir akışından dolayı, futbol kulüplerinin finansal anlamda sıkıntıya düştükleri gözlemlenmiştir. Araştırma neticesinde, İngiliz Premier Ligi (Premier League) ve alt liglerde yer alan futbol kulüplerine çeşitli öneriler ve çözüm politikaları da sunulmuştur.

Frick ve Prinz (2006), futbol endüstrisi üzerine bir çalışma gerçekleştirmişlerdir. Gerçekleştirilen çalışmada, Alman futbol kulüplerinin borçlarının İtalyan ve İngiliz futbol kulüplerinin toplam borçlarının yarısı kadar olduğu saptanmıştır. Aynı zamanda, Alman futbol kulüplerinin ağırlıklı olarak öz sermaye ile finanse edildikleri sonucuna varılmıştır.

Huang ve Chao-Lin, (2006), Tayvan'da bir araştırma yürütmüşlerdir. $\mathrm{Bu}$ çalışmada, satın alma karar sürecine konsantre olunmuştur. Tayvan'da gerçekleştirilen bu çalışmada, dikey analiz yöntemi, işletmelerin satın alma kararlarında kullanılmıştır.

Duque ve Brantes Ferreira (2004), futbol endüstrisi üzerine bir araştırma gerçekleştirmişlerdir. İlgili çalışmanın evrenini, Portekiz Lizbon Borsası'nda işlem gören futbol kulüpleri oluşturmaktadır. Yapılan çalı̧̧mada, Portekiz Lizbon Borsası'nda işlem gören futbol kulüplerinin müsabaka sonuçları ile hisse senetleri fiyatları arasında pozitif yönlü bir ilişki saptanmıştır.

\section{Finansal Fair Play}

Futbol kulüplerinin finansal performansları hususunda, özellikle son yıllarda Union of Football Associations'in (UEFA) geliştirdiği ve sunduğu finansal fair play'ın da önemi büyüktür. UEFA, finansal fair play uygulamasını her yıl geliştirmekte ve en çok üzerinde durduğu 
projelerden biri olarak ifade etmektedir. UEFA'ya göre, finansal fair play uygulamasına geçişten sonra futbol kulüplerinin borçları belirgin olarak düşmüştür. Finansal fair play kavramı ve yönetmeliği UEFA tarafından ilk olarak Eylül 2009'da ortaya atılmıştır. Haziran 2010' da ise finansal fair play uygulanmaya başlamıştır. Finansal fair play'ın amaçları ise genel olarak futbol kulüplerinin ekonomik ve finansal durumlarının iyileştirilmesi, şeffaflık ve kredibilitenin artırılması, futbol kulüplerinden alacaklı kurumların korunması, futbol kulüplerinin çalışanlarına ve vergi otoriteleriyle diğer kulüplere borçlarını ödemelerinin teminat altına alınması, futbol kulüplerinin finansal durumlarının disiplin ve rasyonalite gözetilerek yönetilmesi, futbol kulüplerinin kendi gelirleri ile faaliyetlerini sürdürebilmesinin sağlanması, futbol camiasında sorumluluk çerçevesinde yatırım ve harcamaların yapılması ile Avrupa futbolunun devamlılığının sağlanması olarak özetlenebilir (UEFA, 2021).

Günümüzde, futbol sadece bir eğlence sektörü olmanin ötesine geçmiş ve sanayileşmiştir. Özellikle geçmiş yıllarla karşılaştırma yapıldığında, futbolcu maaşları ciddi anlamda yükselmiş, sponsorluk tutarları artmış ve futbol endüstrisi içerisinde dönen meblağlar ciddi boyutlara ulaşmıştır. Rekabetin de kızıştığı futbol camiasında, futbol kulüpleri büyük harcamalar yapma eğiliminde olmuşlardır. Bu nedenden ötürü, UEFA gelirlerinin üzerinden harcama yapan kulüpleri takip altına alarak belirli kriterler bazında yaptırımlar uygulama kararı almıştır. Böylelikle, finansal fair play da futbol kulüplerinin finansal performansları hususunda bir ölçüt haline gelmiştir (Teker ve Gök, 2019, s.846-859).

Buna karşın, Türkiye'de futbol kulüplerinin finansal fair play yönetmeliğine uyumu konusunda bir takım problemler söz konusu olmuştur. UEFA tarafından finansal fair play kavramı ile yönetmeliğinin ilk çıkış tarihi olan 2009'dan bu yana, Türk futbol kulüpleri finansal fair play'e uygum konusunda zorlanmışlardır. Bu husus özellikle de halka açık Türk futbol kulüpleri için geçerlidir. Negatif özsermaye, başbaşa noktası problemi, yüksek net borçlar ve astronomik futbolcu ücretleri Türk futbol kulüplerinin başlıca problemleri olarak göze çarpmıştır (Karadeniz Koşan ve Günay, 2016, s.250-269).

Belirtilen hususla ilgili olarak, Türk futbol kulüplerinin ekonomik altyapılarındaki eksikliklerin yanında, idari ve yönetimsel anlamda 
eksiklikleri de ön plana çıkmaktadır. Bu durum, Türk futbolunun Türkiye dişında uluslararası arenada rekabetçiliğini de etkilemektedir. Hiç şüphesiz, ekonomik ve idari anlamda aşama kat edebilmek için Türk futbolunda bir takım düzenleme ile yapısal reformların gerçekleştirilmesi şart gözükmektedir (Sevim ve Bülbül, 2017, s.187-212).

Finansal fair play'e uyum konusunda yaşanan başarısızlıklar, tüm Dünya'da olduğu gibi Türkiye'de de futbol kulüplerinin bir açmaza sürüklemektedir. Zira, Türk futbol kulüplerinin finansal fair play'e zorunlu uyumları transfer potansiyellerini ve rekabetçiliklerini kısitlamaktadır. Aynı zamanda, finansal fair play'e uymayan futbol kulüpleri de UEFA'nın müsabakalarından men edilmekte, bu durum kulüplerin finansal durumlarını daha da zora sokmakta ve kaynaklarını sinırlandırmaktadır. Bu nedenden ötürü, Türk futbol kulüpleri için efektif bir muhasebe-finansman yönetimi kaçınılmazdır (Tutar, 2018, s.126-138).

UEFA tarafından finansal fair play kavramı ile yönetmeliğinin ilk sunulduğu yıllarda, Türk futbol kulüplerinin farkındalıkları yüksek düzeyde olmamıştır. İlerleyen yıllarda ise konunun ciddiyeti daha iyi bir şekilde kavranmaya başlanmıştır. Buna karşın, halihazırda Türk futbol kulüplerinin finansal fair play'e uyumlarında hala Avrupa futbol kulüplerinin gerisinde bulundukları gözlemlenmektedir. Bu durum Türk futbol kulüplerinin finansal performanslarını da olumsuz yönde etkilemektedir (Özevin, 2017, s.479-508).

\section{Yöntem}

Türkiye'de futbol, Dünya'daki gelişim ve değişimlere paralel olarak günümüzde belirgin bir şekilde endüstrileşmiştir. Aynı zamanda, Türkiye'deki futbol piyasası ve pazarı ciddi anlamda büyümüş, rekabetçilik ön plana çımıştır. Hiç kuşkusuz, Türkiye'de futbol yıllar içerisinde aşama kaydetmiş, çeşitli birçok farklı sektörle de ilişki içerisine girmiştir. Bunların yanında, UEFA Finansal Fair Play Kuralları da (Düzenlemeleri) Türkiye'de son zamanlarda en çok konuşulan ve tartışılan konuların başında gelmektedir. Dolayısıyla, Türkiye'de futbol kulüplerinin finansal performansının analizi bu noktada geçmişe göre 
çok daha fazla önem arz etmekte, bu çalışmanın da önemli motive edici unsurlarından birini oluşturmaktadır.

Ek olarak, Türkiye'de futbol endüstrisi artık makro düzeyde ülke ekonomisini de yakından ilgilendirdiğinden kritik bir pozisyona sahiptir. Futbol kulüplerinin gelir-gider dengeleri, bilançoları ve yaptıkları transferler medyada yer bulmakta, çeşitli araştırmalara konu olmakta ve hatta zaman zaman kulüp yönetimleri eleştirilere konu olmaktadır. $\mathrm{Bu}$ nedenle, futbol kulüplerinin finansal performansı günümüzde kulüp yönetim becerinin de bir bileşeni olarak algılanmaktadır.

Çalışmanın uygulama kısmı kapsamında, Galatasaray A.Ş.'nin 31.05.2016 - 31.05.2018 tarihleri arasında kamuyla paylaşılmış bilançosundan ve 01.06.2016 - 31.05.2018 tarihleri arasında kamuyla paylaşılmış gelir tablosundan yararlanılmıştır. Dolayısıyla, analize 20152017 dönemine ait mali tablolar dahildir. Bir başka ifadeyle, Borsa İstanbul'a (BİST) kote olan Galatasaray A.Ş.'nin Kamuyu Aydınlatma Platformu'nda yayımlanmış bilanço ve gelir tabloları temel alınmış, mali tablolarındaki yüzdelik değişimler ile belirtilen değişimlerin olası nedenleri belirlenmeye çalışılmıştır. Araştırma aracılığıyla Galatasaray A. S..'nin analiz edilen periyottaki varlık yapısı, kaynak yapısı ile gelir ve gider yapısı mercek altına alınmıştır. Mali tablo kalemlerinin yüzdelik olarak değerlerinin tespiti hususunda aşağıda yer alan formüllerden yararlanılmıştır:

Bilanço Hesaplarının Yüzdesi = İlgili Bilanço Kalemi $/$ Toplam Varlıklar

Gelir Tablosu Hesaplarının Yüzdesi = İlgili Gelir Tablosu Kalemi / Net Satışlar (Hasılat)

\section{Bulgular}

Tablo 1. Galatasaray A.Ş.'nin konsolide olmayan bilançosunun 31.05.2016 31.05.2018 dönemi arası aktif kalemleri ve yüzde cinsinden değerleri (TL)

\begin{tabular}{lllllll}
\hline & $\mathbf{3 1 . 0 5 . 2 0 1 8}$ & $\mathbf{3 1 . 0 5 . 2 0 1 7}$ & $\mathbf{3 1 . 0 5 . 2 0 1 6}$ & $\mathbf{3 1 . 0 5 . 2 0 1 8}$ & $\mathbf{3 1 . 0 5 . 2 0 1 7}$ & $\mathbf{3 1 . 0 5 . 2 0 1 6}$ \\
\hline DÖNEN VARLIKLAR & $\mathbf{5 3 1 . 2 9 0 . 5 9 3}$ & $\mathbf{3 4 5 . 0 6 3 . 4 6 4}$ & $\mathbf{2 5 4 . 1 2 5 . 9 8 2}$ & $\mathbf{0 , 5 4}$ & $\mathbf{0 , 4 5}$ & $\mathbf{0 , 3 6}$ \\
Nakit ve Nakit Benzerleri & 16.388 .940 & 51.482 .221 & 13.695 .030 & 0,02 & 0,07 & 0,02 \\
Ticari Alacaklar & 85.698 .852 & 91.154 .534 & 121.628 .025 & 0,09 & 0,12 & 0,17 \\
Diğer Alacaklar & 377.747 .695 & 141.229 .620 & 55.548 .285 & 0,38 & 0,19 & 0,08 \\
Stoklar & 16.656 .081 & 19.933 .530 & 18.433 .740 & 0,02 & 0,03 & 0,03
\end{tabular}




\begin{tabular}{|c|c|c|c|c|c|c|}
\hline Peşin Ödenmiş Giderler & 28.541 .858 & 29.922 .488 & 34.837 .028 & 0,03 & 0,04 & 0,05 \\
\hline Diğer Dönen Varlıklar & 6.257 .167 & 11.341.071 & 9.983 .874 & 0,01 & 0,01 & 0,01 \\
\hline DURAN VARLIKLAR & 458.844 .776 & 416.009 .547 & 453.772 .473 & 0,46 & 0,55 & 0,64 \\
\hline Ticari Alacaklar & 411.522 & 0 & 2.096 .775 & 0,0004 & - & 0,0030 \\
\hline Diğer Alacaklar & 81.423 & 34.182 & 38.464 & 0,0001 & 0,00004 & 0,0001 \\
\hline Yatırım Amaçlı Gayrimenkuller 2 & 2.375 .000 & 2.320 .000 & 0 & 0,0024 & 0,0030 & 0,00 \\
\hline Maddi Duran Varlıklar & 12.836 .652 & 10.349 .365 & 9.960 .525 & 0,01 & 0,01 & 0,01 \\
\hline Maddi Olmayan Duran Varlıklar] & r151.696.509 & 89.827 .383 & 100.360 .782 & 0,15 & 0,12 & 0,14 \\
\hline Peşin Ödenmiş Giderler & 287.256 .876 & 313.478 .617 & 340.139 .048 & 0,29 & 0,41 & 0,48 \\
\hline Ertelenmiş Vergi Varlığ & 3.664 .452 & 0 & 1.176 .879 & 0,004 & - & 0,002 \\
\hline Diğer Duran Varlıklar & 522.342 & 0 & 0 & 0,0005 & - & 0,00 \\
\hline TOPLAM VARLIKLAR & 990.135 .369 & 761.073.011 & 707.898 .455 & 100 & 100 & 100 \\
\hline
\end{tabular}

Kaynak: Kamuyu Aydınlatma Platformu - KAP (2019). Finansal Tablolar - Galatasaray Sportif Sinai ve Ticari Yatırımlar A.Ş. Kamuyu Aydınlatma Platformu - KAP Websitesi. http://www.kap.gov.tr (Erişim Tarihi: 10.03.2021).

Galatasaray A.Ş. varlıklarındaki değişimin incelenmesi ve değerlendirilmesi hususunda, öncelikle dönen varlıkların ve duran varlıkların toplam varlıklar (toplam aktif) içerisindeki payına bakılmıştır. Dönen varlıkların toplam varlıklar (toplam aktif) içerisindeki payı 2015'de \%36, 2016'da \%45 ve 2017'de \%54 olmuştur. Diğer taraftan, duran varlıkların toplam varlıklar (toplam aktif) içerisindeki payı ise 2015 'de $\% 64$, 2016'da \%55 ve 2017'de \%46 olmuştur. Dolayisiyla, dönen varlıkların toplam varlıklar (toplam aktif) içerisindeki oranı artarken, duran varlıkların ise toplam varlıklar (toplam aktif) içerisindeki oranı azalmaktadır. Dönen varlıklar içerisinde en yüksek pay, 31.05.2018 tarihi itibariyle (2017 yılı) diğer alacaklar kalemine aittir. Duran varlıklar içerisinde en yüksek pay ise 31.05.2018 tarihi itibariyle (2017 yılı) peşin ödenmiş giderler kalemine aittir.

İşletmenin dönen varlıkları altında yer alan nakit ve nakit benzerleri kalemi incelendiğinde, değişken bir seyir izlediği anlaşılmaktadır. Bu kalem 2015 'de toplam aktifin $\% 2$ 'sini, 2016' da \%7'sini ve $2017^{\prime}$ 'de tekrar $\% 2$ 'sini teşkil etmiştir. İşletmenin ticari alacakları ise 2017 'de toplam varlıkların (toplam aktifin) \%17'si iken, 2016'da \%12'sini ve 2017 'de \%9'unu oluşturmuştur. Dolayısıyla, işletmenin ticari alacaklarının toplam varlıklar (toplam aktif) içerisindeki payı düşmektedir. Bu olumlu bir husustur, zira Galatasaray A.Ş.'nin ticari alacaklarını tahsil ettiğini ve erittiğini göstermektedir. İşletmenin diğer alacaklar kalemi ise artma eğilimindedir. Bu kalem 2015'da toplam varlıkların (toplam aktifin) $\% 8^{\prime}$ sini, 2016 'da $\% 19^{\prime}$ unu ve $2017^{\prime}$ de $\% 38$ 'ini oluşturmuştur. Galatasaray 
A.Ş.'nin diğer alacaklarını tahsil edememesi ve eritememesi, olumsuz bir göstergedir. İşletmenin stokları ise 2015 ve 2016 'da toplam varlıkların (toplam aktifin) \%3'ünü, 2017'de ise \%2'sini oluşturmuştur. Bu husus olumlu bir göstergedir, zira Galatasaray A.Ş.'nin stoklarını eritmekte olduğuna işaret etmektedir.

Firmanın duran varlıklarına bakıldığında, ticari alacaklarının toplam varlıkları (toplam aktifi) içerisindeki payının dalgalı bir seyir izlediği görülmektedir. Ancak, Galatasaray A.Ş.'nin uzun vadeli ticari alacaklarının toplam varlıkları (toplam aktifi) içerisindeki oranının 2017 yılında 2015 yılına göre daha düşük olması avantajlıdır. Buna karşın, duran varlıklar altında yer alan ticari alacaklar kaleminin payı toplam varlıklar (toplam aktif) içerisinde düşüktür. Benzer şekilde, Galatasaray A.Ş.'nin duran varlıkları altında yer alan diğer alacaklar ile yatırım amaçlı gayrimenkuller kalemleri de 2015, 2016 ve 2017 yılları arasında dalgalı bir performans göstermiştir. Fakat, diğer alacaklar ile yatırım amaçlı gayrimenkuller kalemlerinin toplam varlıklar (toplam aktif) içerisinde payı büyük değildir. Galatasaray A.Ş.'nin duran varlıkları altında yer alan maddi duran varlıklar kaleminin tutarı ise 2015 yılından 2017 yılına kadar geçen sürede ve üç yıllık periyotta artış kaydetmesine karşın, bu kalemin toplam varlıklar (toplam aktif) içerisinde pay1 \%1 olarak sabit kalmıştır. Dolayısıyla, Galatasaray A.Ş.'nin maddi duran varlıklar kalemi de toplam varlıklar (toplam aktif) kalemi içerisinde önemli bir paya sahip değildir. Galatasaray A.Ş.'nin duran varlıkları altında yer alan maddi olmayan duran varlıklarının toplam varlıklar (toplam aktif) içerisindeki payı 2017'de \%14, 2016' da \%12 ve 2017 ' de \%15 olmuştur, dolayısıyla istikrarlı bir seyir izlememiştir. Diğer taraftan, işletmenin duran varlıklar altında yer alan peşin ödenmiş giderler kaleminin toplam varlıklar (toplam aktif) içerisindeki oranı düşme eğilimindedir. $\mathrm{Bu}$ kalemin toplam varlıklara (toplam aktife) oranı 2017 'de \%48, 2016'da \%41 ve 2017' de \%29 olmuştur. Galatasaray A.Ş.'nin duran varlıkları altında yer alan ertelenmiş vergi varlığ 1 ve diğer duran varlıklar kalemlerinin toplam varlıklar (toplam aktif) içerisinde payı ise yıllar itibariyle değişiklik göstermiştir, ancak her iki kalemin de toplam varlıklar (toplam aktif) içerisindeki oranı oldukça düşüktür. 
Finansal Performansın Yüzde Yöntemi ile Analizi: Galatasaray A.Ş.'ye Yönelik Bir Uygulama

Tablo 2. Galatasaray A.Ş.'nin konsolide olmayan bilançosunun 31.05.2016 31.05.2018 dönemi arası pasif kalemleri ve yüzde cinsinden değerleri (TL)

31.05.20131.05.20131.05.201

31.05.2018 31.05.2017 31.05.2016 8

$7 \quad 6$

\section{KISA VADELİ YÜKÜMLÜLÜKLER}

Finansal Borçlar

Ticari Borçlar

Diğer Borçlar

Çalışanlara Sağlanan Faydalar Kapsamında

Borçlar

Ertelenmiş Gelirler

Borç Karşılıkları

Diğer Kısa Vadeli Yükümlülükler

Dönem Karı Vergi Yükümlülüğü

UZUN VADELİ YÜKÜMLÜLÜKLER

Finansal Borçlar
Ticari Borçlar
Diğer Borçlar
Çalışanlara Sağlanan Faydalar Kapsamında
Borçlar
Ertelenmiş Gelirler
Borç Karşılıkları

Diğer Uzun Vadeli Yükümlülükler

Ertelenmiş Vergi Yükümlülüğü

TOPLAM YÜKÜMLÜLÜKLER

\begin{tabular}{|c|c|c|c|}
\hline $\begin{array}{l}1.079 .829 .8 \\
37\end{array}$ & 553.889 .834 697.201.386 1,09 & 0,73 & \\
\hline 3.553 .878 & 134.674.199 350.117.566 0,53 & 0,18 & 0,49 \\
\hline 5.252 .967 & $141.718 .883121 .092 .3850,22$ & 0,19 & 0,17 \\
\hline 1.449 .138 & $\begin{array}{lll}22.611 .729 & 21.002 .565 & 0,02\end{array}$ & 0,03 & 0,03 \\
\hline
\end{tabular}

247.983.957 190.013.277 120.219.405 0,25 $\begin{array}{lllll}44.782 .515 & 44.588 .122 & 57.288 .841 & 0,05\end{array}$

$\begin{array}{lllll}12.311 .769 & 19.195 .019 & 25.398 .286 & 0,01\end{array}$

$\begin{array}{llll}14.495 .613 & 1.088 .605 & 1.783 .783 & 0,01\end{array}$

$\begin{array}{llll}0 & 0 & 298.555 & 0,00\end{array}$

225.966.862 814.823.926 335.861.028 0,23

$0,25 \quad 0,17$

$0,06 \quad 0,08$

$0,03 \quad 0,04$

$0,00 \quad 0,00$

$0,00 \quad 0,00$

93.395.247 353.800.986 255.094.892 0,0943

$\begin{array}{llll}14.506 .958 & 8.766 .060 & 13.033 .500 & 0,0147\end{array}$

0

$\begin{array}{lllll}58.377 .193 & 56.849 .906 & 17.239 .757 & 0,06\end{array}$

$\begin{array}{lllll}57.887 .201 & 65.060 .012 & 48.961 .836 & 0,06\end{array}$

$\begin{array}{llll}1.477 .567 & 1.366 .638 & 1.176 .539 & 0,0015\end{array}$

$1,07 \quad 0,47$

$\begin{array}{llllll}322.696 & 1.083 .041 & 354.504 & 0,000 & 0,00 & 0,001\end{array}$

$\begin{array}{llllll}0 & 431.881 & 0 & 0,0000 & 0,00 & 0,00\end{array}$

1.305.796.6 $1.368 .713 .7 \quad 1.033 .062 .4$

99

14

$1,32 \quad 1,80 \quad 1,46$

Kaynak: Kamuyu Aydınlatma Platformu - KAP (2019). Finansal Tablolar - Galatasaray Sportif Sinai ve Ticari Yatırımlar A.Ş. Kamuyu Aydınlatma Platformu - KAP Websitesi. http://www.kap.gov.tr (Erişim Tarihi: 10.03.2021).

Galatasaray A.Ş.'nin kaynaklarındaki değişim kapsamında kısa vadeli borçlar (kısa vadeli yabancı kaynaklar), uzun vadeli borçlar (uzun vadeli yabancı kaynaklar) ve özkaynaklar hesapları inceleme altına alınmıştır. Öncelikle, işletmenin kısa vadeli borçları (kısa vadeli yabancı kaynakları) dalgalı bir seyir izlemektedir. Zira, kısa vadeli borçların (kısa vadeli yabancı kaynakların) toplam varlıklar içerisindeki payı 2015'de $\% 98,2016$ 'da \%73 ve 2017'de \%109 olmuştur. Ancak, genel olarak Galatasaray A.Ş.'nin kısa vadeli borçlanma oranının oldukça yüksek olduğunu söylemek mümkündür. Bu husus, işletme açısından olumsuz 
bir tablo oluşturmaktadır. Firmanın kısa vadeli borçları (kısa vadeli tabancı kaynakları) altında en yüksek orana sahip kalemler finansal borçlar, çalışanlara sağlanan faydalar kapsamında borçlar ve ticari borçlar şeklinde listelenebilir. Finansal borçların toplam pasif içerisindeki payı 2015'de \%49, 2016'da \%18 ve 2017'de \%53 şeklinde gerçekleşmiştir. Çalışanlara sağlanan faydalar kapsamında borçlar kaleminin toplam pasif içerisindeki payı 2015 'de \%17, 2016'da \%25 ve 2017'de \%25 şeklinde gerçekleşmiştir. Ticari borçlar kaleminin toplam pasif içerisindeki payı ise $2015^{\prime}$ de $\% 17$, 2016'da \%19 ve $2017^{\prime}$ de $\% 22$ olmuştur. Kısa vadeli borçlar (kısa vadeli yabancı kaynaklar) içerisindeki diğer kalemlerin toplam pasife oranı yüksek bir seviyede değildir.

Firmanın uzun vadeli borçları (uzun vadeli yabancı kaynakları) da yıllar itibariyle istikrarsız bir performans göstermiştir. Galatasaray A.Ş.'nin uzun vadeli borçlarının (uzun vadeli yabancı kaynaklarının) toplam pasif içerisindeki oranı 2015'de \%47, 2016'da \%107 ve 2017'de \%23 olmuştur. İşletmenin uzun vadeli borçlarının (uzun vadeli yabancı kaynaklarının) 2017 yılında 2015 ve 2016 yıllarına göre toplam pasif içerisindeki oranının düşmesi her ne kadar olumlu gibi gözükse de, Galatasaray A.Ş.'nin kısa vadeli yabancı kaynaklarının (kısa vadeli borçlarının) toplam pasif içerisindeki oranı 2017 yılında 2015 ve 2016 yıllarına göre yükselmiştir. Dolayısıyla, uzun vadeli borçların oranının düşmesinin yansıması kısa vadeli borçların oranının yükselmesi şeklinde olmuştur. İşletmenin uzun vadeli borçları (uzun vadeli yabancı kaynakları) içerisinde en yüksek paya sahip kalemler finansal borçlar, çalışanlara sağlanan faydalar kapsamında borçlar, ertelenmiş gelirler ve ticari borçlardır.

Belirtilen hususların yanında, Galatasaray A.Ş.'nin finansal borçlarının tutarı 2017 yılında oransal olarak oldukça artmış, toplam pasif içerisindeki payı da ticari borçların iki katından fazlasına yükselmiştir. Tablodan da anlaşılacağı üzere, finansal borçların toplam pasif içerisindeki oranı 2017 'de \%53, ticari borçların toplam pasif içerisindeki oranı ise 2017 'de \%22'dir. Bu husus, Galatasaray A.Ş. açısından olumsuz bir durum teşkil etmektedir. Zira, ticari borçlar daha esnek bir yapı arz ederken, finansal borçlarda böyle bir esneklik söz konusu değildir. Bir başka ifadeyle, finansal borçlar çok daha katıdır. İşletmenin bu noktada bir önlem alması gereklidir. 
Çalışanlara sağlanan faydalar kaleminin tutarı da 2015 yılından 2017 yılına kadar üç senelik periyotta daima artış göstermiştir. Bu kalemin toplam pasife oran ise 2015 'de $\% 17,2016$ 'da $\% 25$ ve 2017 'de $\% 25$ şeklinde gerçekleşmiştir. İşletmenin, bu kalemi de dikkatli bir şekilde izlemesi şarttır. Kısa vadeli borçlar (kısa vadeli yabancı kaynaklar) altında diğer borçlar, ertelenmiş gelirler, borç karşılıkları, diğer kısa vadeli yükümlülükler ve dönem karı vergi yükümlülüğü kalemlerinin ise toplam pasif içerisindeki oranı düşüktür.

İşletmenin uzun vadeli borçları (uzun vadeli yabancı kaynakları) altında yer alan finansal borçlar kaleminin tutarı 2015 yılından 2017 yılına kadar üç senelik periyotta sabit bir seyir izlememiştir. Aynı şekilde, bu kalemin toplam pasif içerisindeki oranı da yıllar itibariyle değişiklik göstermiştir. Finansal borçların toplam pasife oranı 2015 'de $\% 36$, 2016'da \%46 ve 2017' de \%9,43 olmuştur. Bahse konu olan kalemin özellikle 2017'de kontrol altına alınmış olması olumludur. Ancak dikkat edilirse, Galatasaray A.Ş.'nin uzun vadeli yabancı kaynakları (uzun vadeli borçları) altında yer alan finansal borçlar kalemi de dahil olmak üzere ticari borçlar, diğer borçlar, çalışanlara sağlanan faydalar kapsamında borçlar, ertelenmiş gelirler, borç karşılıkları, diğer uzun vadeli yükümlülükler ve ertelenmiş veri yükümlülüğü kalemlerinin tümünün toplam pasif içerisindeki oranı düşüktür.

Aynı zamanda, Galatasaray A.Ş.'nin kısa vadeli borçları (kısa vadeli yabanc1 kaynakları) yalnızca 2016 yılında tutar ve toplam pasife oran olarak uzun vadeli borçlarından (uzun vadeli yabancı kaynaklarından) daha düşük bir şekilde gerçekleşmiştir. 2015 ve 2017 yıllarında ise işletmenin kısa vadeli borçları (kısa vadeli yabancı kaynakları), uzun vadeli borçlarından (uzun vadeli yabancı kaynaklarından) tutar ve toplam pasife oran olarak daha yüksek bir şekilde gerçekleşmiştir. Belirtilen durum, Galatasaray A.Ş.'nin daha düşük tutarlı ve oranlı faiz giderlerine katlanması açısından olumludur. Ancak, borç ödeme vadesinin kısa olması aynı zamanda işletme üzerinde bir baskı unsurunun oluşmasına neden olmaktadır.

Belirtilenlerin yanında, Galatasaray A.Ş.'nin duran varlık toplamlarını uzun vadeli yabancı kaynak (uzun vadeli borç) toplamlarıla da 2015, 2016 ve 2017 yılları için karşılaştırmak doğru bir hamle olacaktır. Zira, işletmenin duran varlıklarının uzun vadeli yabancı kaynaklarını (uzun 
vadeli borçlarını) karşılayıp karşılamadığını görmek kritik bir husustur. Galatasaray A.Ş.'nin duran varlıkları, uzun vadeli yabancı kaynaklarını (uzun vadeli borçlarını) yalnızca 2016 yılında karşılamamaktadır. 2015 ve 2017 yıllarında ise karşılamaktadır. Belirtilen durum, firma açısından olumludur.

Tablo 3. Galatasaray A.Ş.'nin konsolide olmayan bilançosunun 31.05.2016 31.05 .2018 dönemi arası pasif kalemleri ve yüzde cinsinden değerleri (TL) (2)

\begin{tabular}{|c|c|c|c|c|c|c|}
\hline & 31.05 .2018 & 31.05 .2017 & 31.05 .2016 & 31.05 .2018 & \multicolumn{2}{|c|}{ 31.05.201731.05.2016 } \\
\hline ÖZKAYNAKLAR & -315.648 .927 & -607.640 .74 & $9-325.135 .192$ & $-0,32$ & $-0,80$ & $-0,46$ \\
\hline Ödenmiş Sermaye & 540.000 .000 & 21.645 .000 & 21.645 .000 & 0,55 & 0,03 & 0,03 \\
\hline Sermaye Düzeltme Farkları & 3.827 .679 & 3.827 .679 & 3.827 .679 & 0,00 & 0,01 & 0,01 \\
\hline Diğer Kapsamlı Gelirler veya Giderler & r-736.697 & -508.508 & -539.939 & 0,00 & 0,00 & 0,00 \\
\hline Paylara İlişkin Primler & 437.030 .587 & 434.285 .760 & 434.285 .760 & 0,44 & 0,57 & 0,61 \\
\hline Kardan Ayrılan Kısıtlanmış Yedekler & 21.246 .627 & 21.246 .627 & 20.795 .213 & 0,02 & 0,03 & 0,03 \\
\hline Geçmiş Yıllar Zararı & -1.088 .137 .307 & 7-805.600.31 & 9-725.473.310 & $-1,10$ & $-1,06$ & $-1,02$ \\
\hline Net Dönem Karı/ (Zararı) & -228.879 .816 & -282.536 .988 & 8-79.675.595 & $-0,23$ & $-0,37$ & $-0,11$ \\
\hline Kontrol Gücü Olmayan Paylar & -12.403 & & -28.767 & 0,00 & & 0 \\
\hline TOPLAM KAYNAKLAR & 990.135 .369 & 761.073 .011 & 707.898 .455 & 100 & 100 & 100 \\
\hline
\end{tabular}

Kaynak: Kamuyu Aydinlatma Platformu - KAP (2019). Finansal Tablolar - Galatasaray Sportif Sinai ve Ticari Yatırımlar A.Ş. Kamuyu Aydınlatma Platformu - KAP Websitesi. http://www.kap.gov.tr (Erişim Tarihi: 10.03.2021).

Galatasaray A.Ş.'nin kaynaklarındaki değişim kapsamında özkaynaklar kalemine bakıldığında, öncelikle bu kalemin 2015, 2016 ve 2017 yıllarında daima negatif tutarlara sahip olduğu belirtilmelidir. Özkaynaklar kalemi üç yıllık periyotta dalgalı bir seyir izlese de, daima negatif tutarlara sahip olması işletme açısından olumsuz bir tablo çizmektedir. Bu husus, işletmenin kendi özkaynakları yerine kısa vadeli borçlanma (kısa vadeli yabancı kaynak) ve uzun vadeli borçlanma (uzun vadeli yabancı kaynak) ile fonlandığını göstermesi bakımından da finansal kırılganlık teşkil etmektedir. Bunun yanında, belirtilen husus borç verenler tarafında da güvence şeklinde değerlendirilemez.

İşletmenin ödenmiş sermaye tutarı ise 2017 yılında ciddi bir artış göstermiştir. 2015 ve 2016 yıllarında Galatasaray A.Ş.'nin ödenmiş sermaye kaleminin toplam pasife oranı \%3 iken, 2017 yılında bu oran \%55'e yükselmiştir. İşletmenin ödenmiş sermaye tutarının ve toplam pasif içerisindeki oranının yükselmesi Galatasaray A.Ş. adına 
olumludur, ancak geçmiş yıl zararları ve net dönem zararı bu olumlu gelişmenin etkisini ortadan kaldırmıştır.

Firmanın sermaye düzeltme farkları kalemi ise 2015, 2016 ve 2017 yıllarında sabit bir şekilde gerçekleşmiştir. Ancak, bu kalemin oranı toplam pasif içerisinde oldukça düşüktür. Galatasaray A.Ş. özkaynakları altında yer alan diğer kapsamlı gelir veya giderler kalemi 2015, 2016 ve 2017 yıllarında dalgalı bir seyir izlemiştir. Fakat, diğer kapsamlı gelir veya giderler kaleminin toplam pasif içerisindeki oranı yüksek değildir. Dolayısıyla, bu kalem ciddi bir önem teşkil etmemektedir.

Özkaynaklar altında yer alan paylara ilişkin primler kalemi ise 2017 yılında tutar olarak yükselmesine karşın, toplam pasif içerisinde $\% 44$ 'lük bir paya sahip olmuştur. Ancak, bu kalem 2015 yllında toplam pasif içerisinde \%61'lik ve 2016 yılında \%57'lik bir paya sahiptir. Dolayısıyla, Galatasaray A.Ş.'nin paylara ilişkin primler kaleminin oranı toplam pasif içerisinde yıllar itibariyle düşmüştür. Bu işletme açısından olumlu bir gösterge değildir. Kardan ayrılan kısıtlanmış yedekler kaleminde ise durağan bir yapı söz konusudur, bu kalemin tutarı yıllar itibariyle çok fazla bir değişim göstermemiştir. Ancak, kardan ayrılan kısıtlanmış yedekler kaleminin oranı toplam pasif içerisinde düşük olup, 2015 ve 2016 ' da \%3, 2017' de ise \%2 olarak gerçekleşmiştir.

Galatasaray A.Ş.'nin özkaynakları altındaki geçmiş yıl zararı kalemi ise 2015'den 2017'ye kadar üç yıllık periyotta hem tutar, hem de toplam pasife oran anlaminda daima yükselmiştir. Bu kalemin toplam pasife oranı 2015'de - \%102, 2016'da - \%106 ve 2017'de - \%110 olmuştur. Belirtilen durum Galatasaray A.Ş. için olumsuz bir göstergedir ve finansal açıdan risk taşımaktadır. Aynı zamanda, işletme 2015, 2016 ve 2017 'de net dönem zararına maruz kalmıştır. Net dönem zararı kalemi dalgalı bir seyir izlese de, toplam pasif içerisindeki oranının 2016 ve 2017 yıllarında 2015 yılına göre daha yüksek gerçekleşmesi istenmeyen bir durumdur. Net dönem zararı kaleminin toplam pasife oranı 2015'de \%11, 2016'da - \%37 ve 2017'de - \%23 olmuştur. İşletmenin net dönem zararı kalemiyle ilgili önlem alması, Galatasaray A.Ş.'nin net dönem karı elde etmesi gereklidir. Son olarak, işletmenin özkaynakları altında yer alan kontrol gücü olmayan paylar kalemi statik bir seyir izlememiştir. Ancak, bu kalemin toplam pasife oranı oldukça düşüktür. 
Tablo 4. Galatasaray A.Ş.'nin konsolide olmayan gelir tablosunun 01.06.2016 31.05.2018 dönemi arası yüzde cinsinden değerleri $(T L)$

\begin{tabular}{lllll}
\hline & $\mathbf{0 1 . 0 6 . 2 0 1 7 -}$ & $\mathbf{0 1 . 0 6 . 2 0 1 6 -}$ & $\mathbf{0 1 . 0 6 . 2 0 1 7 -}$ & $\mathbf{0 1 . 0 6 . 2 0 1 6 -}$ \\
& $\mathbf{3 1 . 0 5 . 2 0 1 8}$ & $\mathbf{3 1 . 0 5 . 2 0 1 7}$ & $\mathbf{3 1 . 0 5 . 2 0 1 8}$ & $\mathbf{3 1 . 0 5 . 2 0 1 7}$ \\
\hline KAR VEYA ZARAR KISMI & & & & \\
Net Satışlar (Hasılat) & $\mathbf{6 2 7 . 3 4 4 . 7 0 1}$ & 385.194 .565 & $\mathbf{1 0 0}$ & $\mathbf{1 0 0}$ \\
Satışların Maliyeti (-) & -658.679 .910 & -455.962 .653 & $-1,05$ & $\mathbf{- 1 , 1 8}$ \\
\hline BRÜT ZARAR & -31.335 .209 & -70.768 .088 & $\mathbf{- 0 , 0 5}$ & $\mathbf{- 0 , 1 8}$ \\
Genel Yönetim Giderleri (-) & -18.297 .238 & -13.217 .059 & $-0,03$ & $-0,03$ \\
Pazarlama Giderleri (-) & -24.694 .633 & -22.754 .396 & $-0,04$ & $-0,06$ \\
Esas Faaliyetlerden Diğer Gelirler & 6.586 .853 & 8.296 .785 & 0,01 & 0,02 \\
Esas Faaliyetlerden Diğer Giderler (-)-51.483.707 & -50.097 .166 & $-0,08$ & $-0,13$ \\
\hline ESAS FAALIYET ZARARI & $\mathbf{- 1 1 9 . 2 2 3 . 9 3 4}$ & $\mathbf{- 1 4 8 . 5 3 9 . 9 2 4}$ & $\mathbf{- 0 , 1 9}$ & $\mathbf{- 0 , 3 9}$ \\
Yatırım Faaliyetlerinden Gelirler & 55.000 & 0 & 0,0001 & 0,00 \\
Yatırım Faaliyetlerinden Giderler (-) & -306.210 & -1.250 .870 & $-0,0005$ & $-0,0032$ \\
Finansman Gelirleri & 46.059 .270 & 4.983 .050 & 0,073 & 0,013 \\
Finansman Giderleri (-) & -159.572 .678 & -136.091 .717 & $-0,25$ & $-0,35$ \\
\hline VERGİ ÖNCESİ ZARAR & $\mathbf{- 2 3 2 . 9 8 8 . 5 5 2}$ & $\mathbf{- 2 8 0 . 8 9 9 . 4 6 1}$ & $\mathbf{- 0 , 3 7}$ & $\mathbf{- 0 , 7 3}$ \\
Ertelenmiş Vergi Gideri & 4.096 .333 & -1.608 .760 & 0,007 & $-0,0042$ \\
Kontrol Gücü Olmayan Paylar & -12.403 & 28.767 & $-0,00002$ & 0,0001 \\
DÖNEM ZARARI & $\mathbf{- 2 2 8 . 8 7 9 . 8 1 6}$ & $\mathbf{- 2 8 2 . 5 3 6 . 9 8 8}$ & $\mathbf{- 0 , 3 6 5}$ & $\mathbf{- 0 , 7 3}$ \\
\hline
\end{tabular}

Kaynak: Kamuyu Aydinlatma Platformu - KAP (2019). Finansal Tablolar - Galatasaray Sportif Sinai ve Ticari Yatırımlar A.Ş. Kamuyu Aydınlatma Platformu - KAP Websitesi. http://www.kap.gov.tr (Erişim Tarihi: 10.03.2021).

Galatasaray A.Ş.'nin gelir tablosu kalemleri ve yüzde cinsinden değerleri 01.06.2016 - 31.05.2018 dönemi arası analiz edildiğinde, öncelikle net satışlarının (hasılatının) arttığı görülmektedir. İşletmenin net satışlarında (hasılatında) ciddi bir artışın meydana gelmesi olumlu bir göstergedir. Ancak, Galatasaray A.Ş'nin satışların maliyeti kalemi de artış göstermiştir. Satışların maliyeti tutarı 01.06.2016 - 31.05.2017 dönemi için net satışların (hasılatın) \%118'ini oluştururken, bu oran 01.06.2017 - 31.05.2018 dönemi için net satışların (hasılatın) \%105'ini oluşturmuştur. Her ne kadar belirtilen kalemin net satışlar (hasılat) kalemine oranı düşse de, satışların maliyetinin net satışlardan (hasılattan) her iki dönemde de yüksek olması olumsuz bir finansal göstergedir.

Firmanın brüt zararı ise 01.06.2017 - 31.05.2018 döneminde, 01.06.2016 - 31.05.2017 dönemine göre düşmüştür. Aynı zamanda, brüt zararın net satışlar (hasılat) kalemine oranı da \%18'den \%5'e düşmüştür. Ancak, Galatasaray A.Ş. brüt kar değil, brüt zarar ile karşı karşıyadır. Bunların yanında, işletmenin faaliyet giderleri kapsamında genel yönetim 
giderleri de yükselmiştir. Bu kalemin net satışlar (hasılat) kalemine oranı ise her iki dönemde de sabittir. Galatasaray A.Ş.'nin faaliyet giderleri kapsamında pazarlama giderleri de artmıştır. Fakat, ilgili kalemin net satışlar (hasılat) kalemine oranı 01.06.2017 - 31.05.2018 döneminde, 01.06.2016 - 31.05.2017 dönemine göre düşmüştür.

Galatasaray A.Ş.'nin esas faaliyetlerden diğer gelirler kaleminin tutarında düşüş gerçekleşmiştir. Aynı zamanda, bu kalemin net satışlar (hasılat) kalemine oranı da \%2'den \%1'e gerilemiştir. Bu husus, firma için olumsuz bir göstergedir. Diğer taraftan, işletmenin esas faaliyetlerden diğer giderler kaleminde artış gözlemlenmiştir. Bu kalemin net satışlar (hasılat) kalemine oranı ise azalmıştır. Galatasaray A.Ş.'nin esas faaliyet zararı kaleminin tutarı ise düşmüştür. Ek olarak, bu kalemin net satışlar (hasılat) kalemine oranı da azalmıştır. Belirtilen hususlar kısmen olumlu gibi gözükse de, işletme esas faaliyet karı değil, esas faaliyet zararı ile karşı karşıyadır.

İşletmenin finansman gelirlerinde artış oluşmuştur, ancak bu kalemin net satışlar (hasılat) kalemine oranı düşüktür. Galatasaray A.Ş.'nin finansman giderleri ise artmıştır, ancak ilgili kalemin net satışlar (hasılat) kalemine oranı azalmıştır. İşletmenin vergi öncesi zararı düşmüş, bu kalemin net satışlar (hasılat) kalemine oranı azalmıştır. Bu durum kısmen olumlu gibi gözükse de, işletme vergi öncesi kar değil, vergi öncesi zarar ile karşı karşıyadır.

Galatasaray A.Ş’nin ertelenmiş vergi gideri kaleminde artış, kontrol gücü olmayan paylar kaleminde ise azalış gerçekleşmiştir. Ancak, ertelenmiş vergi gideri ve kontrol gücü olmayan paylar kalemleri net satışlar (hasılat) kalemiyle karşılaştırıldığında düşük tutarlara sahiptir. İşletmenin dönem zararı ise azalmıştır. Aynı zamanda, dönem zararının net satışlara (hasılata) olan oranı da düşmüştür. Bu husus her ne kadar olumlu gibi gözükse de, Galatasaray A.Ş.'de nihayetinde dönem karı değil, dönem zararı oluşmuştur. Brüt zarar, esas faaliyet zararı, vergi öncesi zarar ve dönem zararı kalemlerindeki düşüş ise daha çok net satışlardaki (hasılattaki) artıştan kaynaklanmaktadır.

\section{Tartışma ve Sonuç}


Finansal tabloların analizinden birçok işletme paydaşı yararlanmaktadır. Bunların başında da yatırımcılar, bankalar ve kredi verenler gelmektedir. Dolayısıyla, işletmelerin mali tablolarının doğru olması ve finansal tablolar analizinin gerçekleri yansıtması şeffaflık açısından oldukça faydalıdır. Bu durum, muhasebenin genel kavramlarından sosyal sorumluluk kavramının da yerine getirilmesini sağlamaktadır.

İşletmelerin geçmiş finansal performanslarının ortaya konulması ve gelecek finansal performansları hakkında fikir sahibi olunması, ancak finansal tablolar analizi sayesinde mümkün olur. Finansal tablolar analizi kapsamında yatay analiz (karşılaştırmalı tablolar analizi), dikey analiz (yüzde yöntemi analizi), trend analizi ve oran analizi (rasyo analizi) olmak üzere dört temel yöntem mevcuttur. Bunlardan dikey analiz (yüzde yöntemi analizi), çalışmanın konusunu ve uygulama kısmını teşkil etmiştir. Dikey analiz (yüzde yöntemi analizi) her ne kadar statik bir analiz olsa da, çeşitli üstün yönleri bulunmaktadır. Belirtilen yöntem sayesinde işletmelerin durumu tek bir dönem için net bir şekilde görülebilir, mali tablo hesapları yüzdeler şeklinde özetlenebilir, hesapların ağırlığı anlaşılabilir ve karşılaştırmalar yapılabilir.

Çalışmada, Galatasaray A.Ş.'nin 31.05.2016 - 31.05.2018 tarihleri arasında kamuyla paylaşılmış bilançosundan ve 01.06.2016 - 31.05.2018 tarihleri arasında kamuyla paylaşılmış gelir tablosundan yararlanılarak mali tablolarındaki yüzdelik değişimler ile belirtilen değişimlerin olası nedenleri dikey analiz aracılığıyla belirlenmeye çalışılmıştır. Dolayısıyla, analize 2015-2017 dönemine ait mali tablolar dahildir. Aynı zamanda firmanın varlık yapısı, kaynak yapısı ile gelir ve gider yapısı incelenmiştir. İşletmenin net satışları (hasılatı) yükselmiş olsa da, satışların maliyeti kalemi de yükselmiştir. Hatta, Galatasaray A.Ş.'nin satışların maliyeti kalemi her iki dönem için de net satışlar (hasılat) kaleminden daha yüksektir. Bu durum, işletmenin karlılığını düşürmektedir. Firmanın maliyetlerini kontrol altına alması gerekmektedir. Aynı zamanda, faaliyetler giderleri altında yer alan genel yönetim giderleri ile pazarlama giderleri de artmaktadır. Ek olarak, işletmenin finansman giderleri de yükselmektedir. Galatasaray A.Ş.'nin belirtilen noktalar konusunda da önlem alması şarttır.

İşletmenin varlık yapısı ve kaynak yapısı hususunda da olumlu bir tablo mevcut değildir. Öncelikle, firmanın net işletme sermayesi 
negatiftir. İşletmenin dönen varlıkları, kısa vadeli yabancı kaynaklarını (kısa vadeli borçlarını) karşılayamamaktadır. Aynı zamanda, işletme özsermaye ağırlıklı bir kaynak yapısına sahip değildir. Kısa vadeli yabancı kaynaklar (kısa vadeli borçlar) ve uzun vadeli yabancı kaynaklar (uzun vadeli borçlar) ile finanse edilmektedir. Belirtilen hususlar, bilanço açısından zayıflık teşkil etmektedir. Firmanın finansal borçlarının ticari borçlarından yüksek olması da esnekliğe imkan tanımaması nedeniyle tehlikelidir. Galatasaray A.Ş.'nin diğer alacaklar kaleminin artması da negatif bir durumdur. Ayrıca, firmanın negatif özsermayeye sahip olması, geçmiş yıl zararları ve net dönem zararı ile karşı karşıya olması finansal risk ve kırılganlık teşkil etmektedir.

Son olarak, firmanın stoklarını eritmesi ve ticari alacaklarını azaltması ise pozitif hususlardır. Ek olarak, Galatasaray A.Ş.'nin duran varlıkları, uzun vadeli yabancı kaynaklarını (uzun vadeli borçlarını) yalnızca 2017 yılında karşılamamaktadır. 2016 ve 2018 yıllarında ise karşılamaktadır. Belirtilen durum, firma açısından olumludur. Genel olarak Galatasaray A.Ş.'nin finansal açıdan kaydettiği olumlu gelişmeler ve ilerlemeler mevcut olsa da, finansal kırılgan ile risk arz ettiği durumlar ağırlıktadır. 
EXTENDED ABSTRACT

\title{
Investigation of Financial Performance with Vertical Analysis: An Implementation on Galatasaray A.Ş.
}

\author{
Cevdet Kizıl - Tunay Aslan \\ İstanbul Medeniyet University-Siirt University
}

Developments in many areas with globalization have brought along important changes and risks, especially in the fields of accounting and finance. In today's world, the rapid increase in competition, the need for foreign resources, the conditions and where this need will be obtained constitute important risks faced by businesses. Finding solutions to the scarcity of scarce resources and providing these resources at the lowest cost make financial analysis important. While this is important for all businesses, it is also important for football clubs. Intense competition in football clubs increases the importance of financial analysis, and business resources must be used efficiently in order to minimize this effect. The main functions of an effective financial management are financial planning and control. Definitely, their realization depends on an effective financial analysis.

Financial analysis is a branch of science that examines the trends in the changes in the items in the financial statements over time in order to determine the financial situation of a business and whether its financial development is sufficient, and if necessary, compares it with the determined standards and industry averages. In other words, financial analysis is a tool that guides business stakeholders in selecting, evaluating and interpreting financial data, along with other information, to help them make decisions. Financial analysis can be done inside the company on issues such as the performance of the employees, the efficiency of the activities and credit policies, or it can be done outside the company for decisions such as making investment decisions and determining the solvency.

Financial analysis provides us with important information about whether the financial balance of the enterprises is appropriate. Financial analysis also provides an idea about the place and importance of the 
enterprises in the market. Financial analysis reveals the strengths and weaknesses of businesses, which provides an opportunity for stakeholders who want to invest in the business as well. Thus, financial analysis guides information users by presenting the financial situation of business.

In this study, financial analysis, which is important in terms of the financial status of businesses, and vertical analysis method, which is one of these analysis methods, have been tried to be explained. For this purpose, the first part of the study was the introduction part. Afterwards, a literature review on the subject was carried out, and academic studies in which financial analysis was applied as a method were included. In the next part of the study, financial analysis methods and features are explained. In the application part of the study, the vertical percentage method, which is one of the financial analysis methods, was used and the financial situation was analyzed by using the financial statements (balance sheet and income statement) of Galatasaray A.Ş. for the 2015-2017 period. In the last part of the study, there is the conclusion part.

In the research, the company's asset structure, resource structure as well as income and expense structure were examined. Although the net sales (revenue) of the business has increased, the cost of sales has also increased. In fact, the cost of sales of Galatasaray A.Ş. is higher than the net sales (revenue) for both periods. This situation reduces the profitability of the business. The firm needs to control its costs. At the same time, general administrative expenses and marketing expenses, which are under operating expenses, also increase. In addition, the financial expenses of the enterprise are also increasing. Galatasaray A.Ş. must also take precautions regarding the specified points.

There is no positive scenario regarding the asset structure and resource structure of the enterprise. First, the firm's net working capital is negative. The current assets of the enterprise cannot meet its shortterm liabilities (short-term debts). At the same time, the entity does not have an equity-weighted resource structure. It is financed by short-term liabilities (short-term liabilities) and long-term liabilities (long-term liabilities). The mentioned issues constitute a weakness in terms of the balance sheet. The fact that the firm's financial debts are higher than its 
commercial debts is also dangerous because it does not allow flexibility. The increase in other receivables of Galatasaray A.Ş. is also a negative situation. In addition, the fact that the firm has negative equity, is faced with previous year losses and net loss for the period constitutes financial risk and fragility.

Finally, the company's depletion of its stocks and reduction of its trade receivables are positive aspects. In addition, Galatasaray A.Ş.'s fixed assets do not cover its long-term liabilities (long-term debts) only in 2017. But, that is achieved in 2016 and 2018. The stated situation is positive for the company. In general, although there are positive developments and progress made by Galatasaray A.Ş. financially, financial fragile and risky situations are predominant.

\section{Kaynakça/References}

Aslan, T. (2018). Futbol kulüplerinin finansal performansının Oran Yöntemi ile analizi: Bist'de işlem gören futbol kulüpleri üzerine uygulama. Muhasebe ve Vergi Uygulamalarn Dergisi, 11(3), 349-362.

Bardia S. C. (2012). Predicting financial distress and evaluating long-term solvency: An empirical study. The IUP Journal of Accounting Research and Audit Practices, 6(1), 47-61.

Bilici, N. ve Aydın, N. (2018). Konaklama işletmelerinde finansal analizlere ilişkin bir örnek olay incelemesi. Atatürk Üniversitesi Sosyal Bilimler Enstitüsü Dergisi, 22(4), 2333-2355.

Buraimo, B., Simmons, R. ve Szymanski, S. (2006). English football. Journal of Sports Economics, 7(1), 29-46.

Çatı, K., A. Eş ve O. Özeyin. (2017). Futbol takımlarının finansal ve sportif etkinliklerinin entropi ve topsis yöntemiyle analiz edilmesi: Avrupa'nın 5 Büyük Ligi ve Süper Lig üzerine bir uygulama. Uluslararası Yönetim İktisat ve İşletme Dergisi, 13(1), 200-222.

Dimitropoulos, P. (2010). The financial performance of the greek football clubs. Sport Management International Journal, 6(1), 5-28.

Duque, J. ve Brantes Ferreira, A. (2004). Explaining share price performance of football clubs listed on the euronext Lisbon. Instituto Superior De Economia E Gestao, 1-38.

Ersoy, E., Çıtak, L. ve Gülal, Ö. (2015). Yerli ve yabancı futbol kulüplerinin transfer harcamaları bağlamında etkinliklerinin karşılaştırılması. Maliye Finans Yazlarn, 105, 133-152. 
Frick, B. ve Prinz, J. (2006). What crisis? Football in Germany. Journal of Sports Economics, 7(1), 60-75.

Gürkan, D. (2009). Basın işletmelerinin finansman sorunları ve bir finansal analiz uygulaması. İletişim Kuram ve Araştırma Dergisi, 29, 23-52.

Huang, L. ve Chao-Lin. (2006). Exploiting corporate governance and common size analysis for financial distress Detecting Models. In: JCIS, 1-6.

Karadeniz, E., Koşan, L. ve Günay, F. (2016). UEFA finansal Fair Play Kuralları bağlamında Borsa İstanbul'da işlem gören spor şirketlerinin performanslarının analizi. TiSK Akademi, 11(22), 250-269.

Kızıl, C. ve Aslan, T. (2019). Finansal performansın Rasyo Yöntemiyle Analizi: Borsa İstanbul'da (Bist'de) İşlem gören havayolu şirketleri üzerine bir uygulama. MANAS Sosyal Araştırmalar Dergisi (MANAS Journal of Social Studies), 8(2), 1778-1799.

Kızıl, C., Kahve, F. ve Aydınyılmaz, O. (2013). Muhasebe ve finans perspektifinden renault-nissan birleşmesi ile daimler stratejik ortaklı̆̆ı. İstanbul: Derin Yayınları.

Kızıl, C., Selvi Hanişoğlu, G. ve Aslan, T. (2019). Kripto paraların finansal piyasalara etkileri ve muhasebeleştirilmesi. Bursa: Ekin Yayınevi.

Kodal, S. (2017). Borsa İstanbul'da İşlem Gören Bir Turizm İşletmesinin Finansal Oranlar İle Analizi, 1st International Congress on Future of Tourism: Innovation, Entrepreneurship and Sustainability, 645.

Omağ, A. (2014). Yüzde yöntemi ile analiz ve g1da sektörüne yönelik bir uygulama. Finansal Araştırmalar ve Çalışmalar Dergisi, 6(11), 65-82.

Ozolgun, H. (2017). Karşılaştırmalı mali tablolar analizi. Journal Of Emerging Economies And Policy, 2(1), 55-62.

Özevin, O. (2017). UEFA Finansal Fair Play düzenlemesinin Avrupa futbol kulüpleri üzerindeki etkisi: Avrupa 5 büyük ligi ve Türkiye Süper Ligi üzerine bir inceleme. Muhasebe Bilim Dünyası Dergisi, 19(2), 479508.

Özyürek, H. ve Erdoğan, E. (2011). Finansal kurumlarda mali analiz ve bir uygulama. Ekonomi Bilimleri Dergisi, 3(2), 229-238.

Sakınç, İ. (2014). Using grey relational analysis to determine the financial performance of Turkish football clubs. Journal of Economic Library, 1(1), 22-23.

Sevim, A. ve Bülbül, S. (2017). UEFA finansal Fair Play (FFP) kriterleri kapsamında Türk futbolunda finansal raporlamanın önemi ve bir sistem gerekliliği. Kara Harp Okulu Bilim Dergisi, 27(2), 187-212. 
Singh, A.J. ve Schmidgall, R.S. (2013). Does financial performance depend on hotel size? Analysis of the financial profile of the U.S. lodging industry. Hospitality Review, 30(2), 239-256.

Şen, L., Zengin, B. ve Yusubov, F. (2015). Otel işletmelerinde finansal analizlere ilişkin bir örnek olay incelemesi. İşletme Bilimi Dergisi, 3(1), 64-85.

Teker, T. ve Gök, İ. Y. (2019). Finansal Fair Play yaptırımlarının sportif başarı üzerine etkisi. II. International Conference on Empirical Economics and Social Science (ICEESS '19), Bandırma, 846-859.

Tekin, İ. (2017). Finansal analiz teknikleri ve finansal analiz üzerine bir uygulama. Yayınlanmamış Yüksek Lisans Tezi. Adıyaman Üniversitesi Sosyal Bilimler Enstitüsü, İşletme Ana Bilim Dalı, Adıyaman.

Tutar, S. (2021). Finansal Fair Play kriterlerine uyum süreci futbol kulüplerinin muhasebe uygulamalarında manipülatif eylemleri tetikler mi? International Journal of Entrepreneurship and Management Inquiries, 2(2), 126-18.

UEFA. (2021). Financial Fair Play. UEFA Resmi Websitesi. http://uefa.com/insideuefa/protecting-the-gamelfinancial-fair-play (Erişim Tarihi: 25.04.2021).

Vanipriya, R. ve Venkatramaraju, D. (2012). The Financial Performance of Cement Sector, International Journal of Trade \& Global Business Perspectives, 1(1), 36-43.

Yahya, F., Ali, S. A., Mir, Z., Yaqoob, M. ve Khan, U.A. (2013). Significant analysis for financial statements: an empirical study of national and unilever foods. Research Journal of Finance and Accounting, 4(1), 26-34.

\section{Kaynakça Bilgisi / Citation Information}

Kızıl, C. ve Aslan, T. (2021). Finansal performansın Yüzde Yöntemi ile Analizi: Galatasaray A.Ş.'ye yönelik bir uygulama. OPUSUluslararası Toplum Araştırmaları Dergisi, 18(44), 8172-8197. DOI: 10.26466/opus.970515. 